\title{
IMPLANTAÇÃO DA LÓGICA TAMBOR-PULMÃO-CORDA EM UMA EMPRESA DA INDÚSTRIA MOVELEIRA
}

\author{
J. LUCHESE, J. M. BAUER, A. VARGAS, G. G. SAUERESSIG, M. C DE SOUZA e M. A. SELLITTO* \\ Universidade do Vale do Rio dos Sinos (UNISINOS) \\ sellitto@unisinos.br*
}

Artigo submetido em julho/2015 e aceito em dezembro/2015

DOI: $10.15628 /$ holos.2015.3181

\section{RESUMO}

O objetivo deste artigo é analisar os impactos da implantação do TPC (Tambor-Pulmão-Corda), descrevendo as desvantagens observadas antes desta modificação, bem como os benefícios obtidos após as mudanças. O método de pesquisa foi o estudo de caso único, efetuado em uma empresa pertencente ao polo moveleiro de Bento Gonçalves localizado no Rio Grande do Sul. Entre os resultados obtidos com a pesquisa, evidenciaram-se os processos da empresa, o espaço físico, o transporte de peças entre setores e o sequenciamento da produção, prévios a aplicação da metodologia. Constatou-se que a implantação de um sistema TPC foi essencial para que a melhoria dos processos fosse alcançada.

PALAVRAS-CHAVE: Indústria Moveleira, TPC, Tambor-Pulmão-Corda, Teoria das Restrições.

\section{IMPLEMENTATION OF THE DRUM-BUFFER-ROPE LOGIC IN A COMPANY OF THE FURNITURE INDUSTRY}

\begin{abstract}
The objective of this article is to analyze the impacts of implantation of DBR (Drum-Buffer-Rope), describing the disadvantages observed before the modification, as well as the benefits obtained after the changes. The research method was the single case study, accomplished in a company belonged to the Bento Gonçalves municipality (RS, Brazil) furniture center. Between the results
\end{abstract}

achieved with the research, it was pointed out the company processes, the physical space, the transport of parts between departments and the sequencing of production previous to the methodology fulfillment. It was found that the implantation of a DBR system was essential to the improvement of process was achieved.

KEYWORDS: Furniture Industry, DBR, Drum-Buffer-Rope, Theory of Constraints. 


\section{INTRODUÇÃO}

O setor moveleiro no Brasil conta com mais de 18.000 empresas, concentradas em sua maior parte nas regiões Centro-Sul, nos polos moveleiros distribuídos entre as cidades de Bento Gonçalves (RS), Arapongas (PR) e São Paulo (SP) (MOVERGS, 2013 e IEMI, 2014). Estes polos são caracterizados pela governança familiar de organizações, formadas por pessoas como experiência ou ligadas ao ramo e são principalmente compostos por micro e pequenas empresas (a sua grande maioria conta com capital inteiramente nacional)(SOUZA, 2003).

Tais empresas, pressionadas pela alta competitividade do mercado, estão engajadas na busca de alternativas capazes de torná-las mais competitivas. Portanto, umas das opções para obtenção de vantagem competitiva é o gerenciamento e o controle da função produção, com o intuito de melhoria do desempenho, em especial nos critérios qualidade, prazo de entrega e distribuição (PEREIRA et al., 2011). Nesse sentido, muitas empresas vêm adotando inovações tecnológicas, desenvolvendo alterações em seus processos de produtivos e adotando ferramentas tais como o MRP (Manufaturing Resource Planning - Planejamento dos Recursos de Manufatura), a Manufatura Enxuta e a Teoria das Restrições (TOC) composta pela lógica TPC (Tambor-PulmãoCorda) (GEORGIADIS e POLITOU, 2013).

Através do método TPC da teoria das restrições é possível localizar o elemento que restringe o sistema, denominado de gargalo ou recurso com restrição de capacidade (RRC), e estabelecer um ritmo de produção para todo o sistema (SOUZA, 2006).

Quando aplicado na indústria moveleira conforme estudo de Wu, Morris e Gordon (1994), o TPC pode melhorar o tempo de processo de produção, através da diferenciação entre os recursos restritivos daqueles que não o são restritivos, permitindo-se a melhoria no sequenciamento da produção. Portanto, se o ritmo de produção é estabelecido pela restrição a mesma passa a ser mais bem utilizada e evita-se de acordo com Atwater e Chakravorty (2002) interrupções ao longo da operação para que o recurso restritivo permaneça dentro do cronograma de produção, coindose desperdício de capacidade nos recursos não restritivos.

Diante desse contexto, o objetivo geral deste artigo é descrever uma implantação da lógica TPC (Tambor-Pulmão-Corda) em uma empresa da indústria moveleira, que teve como principal propósito diminuir o tempo de atravessamento, melhorar o prazo de entrega e ainda diminuir as perdas durante o processo. O método de pesquisa aplicado foi o estudo de caso simples. Os objetivos específicos delimitados foram: (i) descrever os setores e o processo produtivo da empresa; (ii) descrever os preparativos e procedimentos para implantação do TPC; e (iii) analisar os impactos positivos e negativos da implantação. O restante do artigo está organizado em revisão da literatura acerca da Teoria das Restrições e o método TPC (Tambor-Pulmão-Corda); apresentação da pesquisa; apresentação dos resultados e discussão; e sugestão de futuras pesquisas. 


\section{A TEORIA DAS RESTRIÇÕES}

Conforme Watson et al. (2007) e Tulasi e Rao (2012) a TOC (Teoria das Restrições), a qual é um método de administração da produção, foi desenvolvida pelo físico israelense Eliyahu Goldratt durante os anos 1980, e divulgada a partir do livro de negócios A Meta, de 1984.

Entretanto, as origens da TOC estão relacionadas ao desenvolvimento de um software de programação da produção que ficou conhecido pela sigla OPT (Optimized Production Technology) o qual evoluiu para uma filosofia de gestão denominada de TOC, e que possui em seus métodos o TPC do qual foi originado o software e outras técnicas e ferramentas (MABIN e BALDERSTONE, 2003; BOYD e GUPTA, 2004).

A TOC é um método de estruturação e solução de problemas aplicável a diversas áreas funcionais das empresas, desde produção, serviços, projetos, tomada de decisões, contabilidade e finanças, entre outras (MABIN e BALDERSTONE, 2003).

Ela considera qualquer empresa como um sistema, ou seja, um conjunto de elementos interdependentes responsáveis pelo desempenho global da organização. A TOC direciona seus esforços no gerenciamento do gargalo do sistema (a restrição), ou seja, o elo mais fraco da cadeia, responsável pelo ganho da empresa como um todo, e o qual limita a capacidade da empresa de obter mais resultados, ou seja, de atingir a sua meta que é ganhar mais dinheiro (SCHRAGENHEIM e RONEN, 1990; GOLDRATT e COX, 2002).

Goldratt e Cox (2002) estabelecem que para o alcance da meta deve-se seguir três indicadores, entre: aumentar o ganho (receita), reduzir o inventário/investimento, ou seja, o dinheiro que o sistema investe na compra de coisas que pretende vender; e reduzir a despesa operacional, o dinheiro gasto par a transformação do investimento em ganho.

Para tanto, a empresa deve buscar otimizar os processos pela melhoria global do sistema com apoio nos cinco passos de focalização ou de melhoria contínua. Deve-se evitar o simples aumento da eficiência local (setores ou máquinas isolados), dado que a soma dos ótimos locais não é igual ao ótimo total. A Figura 1 ilustra o processo dos cinco passos de focalização.

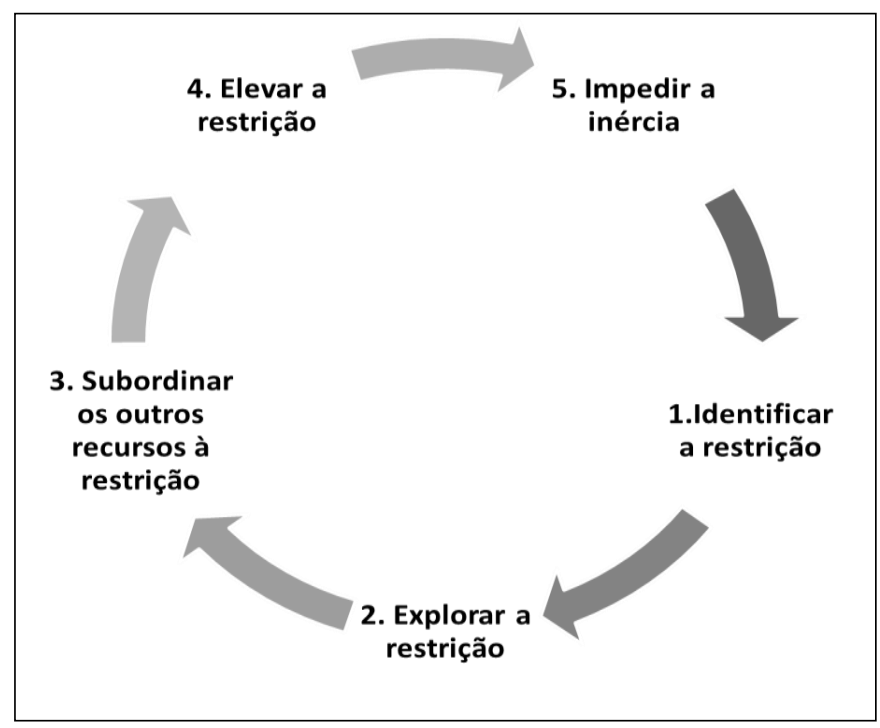

Figura 1: O processo de melhoria contínua. Fonte: Gupta e Kline (2008) e Reid (2008). 
Em síntese, a Teoria das Restrições percebe a organização como uma rede de elos, de funções, de processos, de departamentos ou de recursos interdependentes, onde deve-se despender a energia primeiramente no aumento do ganho ao invés da redução de custos (GUPTA e BOYD, 2008).

\subsection{A lógica Tambor-Pulmão-Corda (TPC)}

A lógica TPC (Tambor-Pulmão-Corda) permite a programação e o controle da produção e tomada de decisão no chão de fábrica (SCHRAGENHEIM e RONEN, 1990). Ela torna a complexidade do fluxo de material mais compreensível; reduz o número de recursos que devem ser programados; alerta para possível interrupção da programação; controla os tempos de atravessamento; fornece orientação para melhorias e direciona a atenção somente para áqueles recursos críticos, em que há requisição programações somente na liberação de materiais para a restrição (GARDINER et al. 1993).

O método TPC identifica e elimina as fontes de variação que causam atrasos no fluxo de materiais no sistema (GEORGIADIS e POLITOU, 2013). Ele é um sistema híbrido que puxa e empurra a produção. As operações anteriores ao gargalo são programadas com base em sua capacidade finita, liberando material conforme as necessidades da restrição. Os materiais são puxados na taxa em que sairão do sistema. Portanto não há acumulação de inventários nos recursos não restritivos e evita-se a produção em excesso e os estoques entre processos (PANIZZOLO e GARENGO, 2013). Já para aquelas operações após o gargalo, a programação pode ser feita com base em capacidade infinita, pois a taxa de chegada de materiais jamais superará a taxa de sáda do gargalo, a qual por definição, é menor que a capacidade das operações faltantes (GARDINER et al., 1993).

O gargalo, conforme Antunes Jr. (1998), deve trabalhar todo o tempo disponível, excluindose preparações e setups. O gargalo deve ser programado na lógica denominada forward (para frente) em que ignora-se a capacidade de recursos não gargalo os quais são programados backward (para trás). Os recursos não gargalo possuem excesso de capacidade, o seu tempo em fila é mínimo, e agiliza-se a recuperação de rupturas, protegendo o ganho (ATWATER e CHAKRAVORTY, 2002; PANIZZOLO e GARENGO, 2013).

Quanto ao tamanho de lotes no TPC, este é variável e as sequências de ordens seguem a lógica "o primeiro a chegar é o primeiro a entrar" (STEELE et al., 2007). Os tamanhos de lotes maiores são utilizados na restrição de modo a reduzir os setups e maximizar a eficiência, ao passo que nos recursos restrititivos os lotes podem ser unitários, já que eles apresentam excesso de capacidade e comportam maior tempo para setups. Os grandes lotes de processamento reduzem os setups na restrição e pequenos lotes de transferência aceleram o fluxo de material (GUPTA e BOYD, 2008).

O TPC baseia-se é estruturado nos mecanismos: Tambor (T), Pulmão (P) e Corda (C). $O$ tambor é responsável por definir o ritmo de produção e de todos os demais processos subordinados. Com isto, uma data realista pode ser dada ao cliente (CHAKRAVORTY e ATWATER, 2005; SOUZA, 2006).

Em oposição ao Kanban, o TPC não requer estoque de material na frente de cada recurso (GARDINER et al., 1993), o que reduz tempos de atravessamento, inventário, e as despesas operacionais, os quais representam custos para as organizações, e em decorrência redução do 
ganho final. Os estoques somente são admitidos em locais estratégicos, relativos aos poucos recursos restritivos (SOUZA, 2006). Estes estoques (denominados de pulmões), evitam interrupções no gargalo, já que as interrupções que ocorram fora deste podem ser compensadas pela capacidade excessiva dos outros recursos. O tamanho dos pulmões é definido de modo a compensar as flutuações estatísticas na capacidade fora do gargalo (SCHRAGENHEIM e RONEN, 1990; GUPTA e BOYD, 2008). As novas ordens de produção são liberadas algum tempo antes do programado, de modo a prevenirque o gargalo pare por falta de trabalho (SCHRAGENHEIM e RONEN, 1990).

Por fim a corda, é um dispositivo de comunicação, e que assegura que a restrição não tenha excesso ou falta de ordens, e sincroniza novas liberações no início da linha com o conteúdo do pulmão (SRINIVASAN et al., 2004). O comprimento da corda é o tempo requerido para manter o pulmão cheio mais o tempo de processamento desde o início do processo até a chegada ao pulmão (SOUZA, 2006; WATSON et al., 2007).

\section{METODOLOGIA}

A empresa objeto deste estudo foi uma organização pertencente ao cluster moveleiro de Bento Gonçalves, que atua há mais de 35 anos no mercado. A empresa conta com 55 funcionários, uma área de $15.000 \mathrm{~m}^{2}$, das quais $4.500 \mathrm{~m}^{2}$ de área construída destinada exclusivamente para fabricação de estofados, sofás-camas, poltronas e pufes direcionados para clientes das classes $\mathrm{A}$, B e C. São mais de 110 modelos de produtos e 570 de revestimentos, de distintos tecidos, cores e tonalidades. A empresa por obrigatoriedade mantém em estoque estes tecidos não somente devido a todos os produtos serem customizados, mas seguindo uma linha de tendências de mercado. Comprando lotes mínimos de 60m para cada SKU (Stock Keeping Unit), quantidade padrão de compra para minimizar custos de transporte ou em função dos fornecedores estabelecerem lotes mínimos de compra. Um diferencial da empresa é a possibilidade de customização conforme necessidade de clientes, (produção make-to-order) o que dificulta previsões de demanda. Os clientes localizam-se principalmente no Rio Grande do Sul, São Paulo e Rio de Janeiro.

A abordagem foi qualitativa, na qual se considera haver uma relação entre a realidade e o sujeito e se realiza a intepretação dos fenômenos, atribuindo-Ihe significados (SILVA; MENEZES, 2005). O nível de pesquisa foi descritivo. Neste tipo de pesquisa estuda-se, analisa-se e registramse os fatos sem a interferência do pesquisador, não se explicando o fenômeno de investigação, apenas descrevendo-o (GIL, 2010; ACEVEDO; NOHARA, 2013; MEDEIROS, 2011). Para a obtenção dos dados o procedimento adotado foi a pesquisa bibliográfica e a observação não participante do processo produtivo da empresa. Além disso, foram realizadas entrevistas com múltiplas fontes relacionadas à área de produção, com base em um protocolo que contém os construtos de pesquisa (Tabela 1), com profissionais que acompanham e gerenciam o processo produtivo da empresa, e foram selecionados em função dos conhecimentos acerca da implantação do TPC. Entre estes se menciona: gerente de produção, diretor da empresa e supervisores de produção. 
Tabela 1: Construtos de pesquisa.

\begin{tabular}{c|c}
\hline Tema & Desenvolvimento \\
\hline Produto final & Identificação dos produtos produzidos na empresa \\
\hline Processo Produtivo & Descrição do processo produtivo \\
\hline $\begin{array}{c}\text { Problemas no Processo } \\
\text { Produtivo }\end{array}$ & $\begin{array}{c}\text { Descrição dos inconvenientes e problemas no processo produtivo } \\
\text { antes da implantação do TPC }\end{array}$ \\
\hline TPC (Tambor-Pulmão-Corda) & Descrição de como foi implantado o método \\
\hline Benefícios & Identificação dos benefícios e melhoria obtidos com o TPC \\
\hline Desafios & Quais as dificuldades ou desafios para a implantação \\
\hline
\end{tabular}

\section{RESULTADOS}

\subsection{Descrição do Processo Produtivo}

O processo de produção de estofados em geral inicia-se na marcenaria, com o corte da madeira compensado OSB e papelão conforme os modelos e moldes, formando a estrutura, permanecendo estocados até seguirem para o setor de montagem inicial onde as peças advindas da marcenaria são montadas, formando os braços, a base, o assento e o encosto do estofado.

No mesmo setor de montagem, são incluídos ainda acessórios como molas e percintas (cintas elásticas) nos assentos e encostos das poltronas, conforme as especificações de cada modelo, como também são inseridas molas e papelão se necessário, observadas na Figura 1.

Simultaneamente, são cortadas as espumas e fibras, que seguem para o setor de colagem, responsáveis por colar a espuma nos encostos dos assentos e braços do estofado produzidos na marcenaria. A espuma e a fibra é aplicada na quantidade e densidade necessária ao conforto conforme as especificações técnicas de cada modelo e então sendo encaminhado para o setor de estofaria onde são estocadas as estruturas semiacabadas.

Paralelamente ocorre a fabricação da capa de tecido o qual é cortado e costurado conforme modelo especificado no pedido. Na estofaria há o encontro das peças vindas da montagem inicial já com a espuma e das capas de tecidos vindas da costura, nesta etapa as peças são ensacadas ou estofadas com a capa de tecido sendo que esta é fixada com grampos.

Na montagem final os braços, caixa, assento e encosto até então em peças soltas, são unidas com grampos e ou parafusos, dando forma ao estofado. No setor seguinte, são colocados todos os acessórios e acabamentos como pés, bases, madeira, alumínios, braços e almofadas.

O estofado, já pronto segue então para a embalagem onde são colocadas cantoneiras de papelão nos pés, bases e cantos dos estofados, e após o estofado é embalado, etiquetado e levado até a expedição, o que pode ser verificado através da Figura 2, onde são ilustradas as fases do processo produtivo da empresa. 


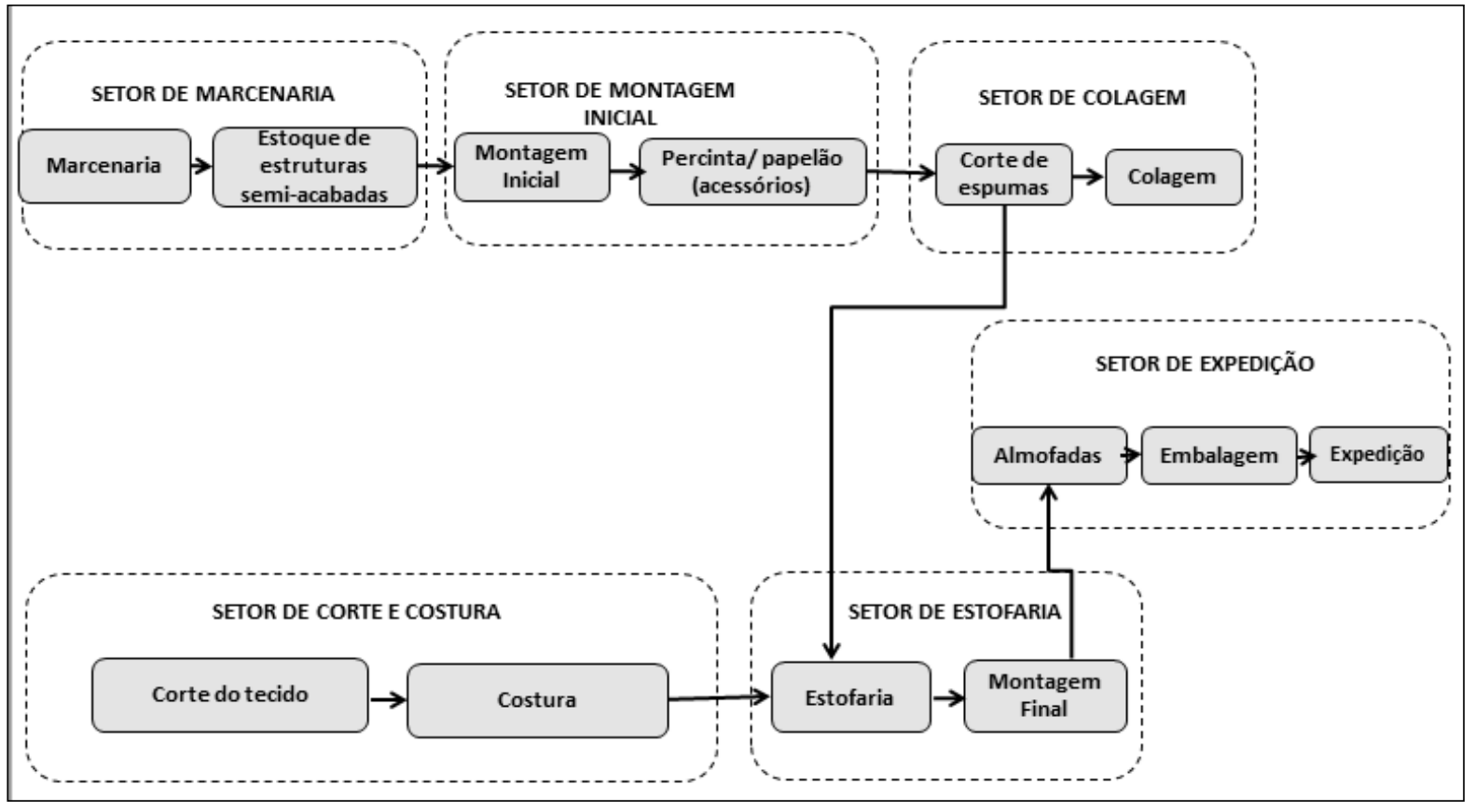

Figura 2: 0 sistema produtivo. Fonte: Elaboração própria

Em todos os setores antes de serem encaminhadas para o setor seguinte as peças são inspecionadas para evitar retrabalhos nos setores seguintes.

O fluxo de produção na empresa, como observado, é caracterizado como do tipo "V" que de acordo com Souza (2006) apresenta operações divergentes no início de sua estrutura impossibilitando modificações nos pedidos caso estas sejam necessárias, sendo em cada operação o produto transformado em vários diferentes (neste caso estrutura, encosto, pés, braços, almofadas). Neste tipo de planta apresenta-se frequentemente a produção maior do que necessária de itens errôneos, principalmente por empregarem-se lotes grandes, acarretando em altos níveis de estoque de produtos em processo, baixo desempenho nas entregas e conflitos entre departamentos na produção. No total, operam 42 funcionários da produção.

\subsection{O ambiente organizacional prévio}

Antes da implantação do TPC a empresa havia realizado uma modificação em seu layout, caracterizado como funcional. Tais mudanças ocorreram devido ao espaço limitado entre os setores, dificultando o transporte das peças; o pouco espaço para armazenamento de peças maiores, como as estruturas dos sofás e encostos e assentos que quando inteiras podem ultrapassar de 2,5 a 3 metros de largura; muitas peças eram empilhadas umas sobre as outras, acarretando em peças avariadas por más condições de armazenamento, forçando um novo retrabalho. Além disso, os setores não estavam sem sequência de processo, fazendo com que as peças fizessem movimento de ida e volta desnecessária e averiguavam-se muitas peças pequenas perdidas entre os processos, requisitando-se a produção duplicada.

A primeira alteração no layout foi um espaço maior para o setor da marcenaria e os estoques de madeira, tais como o MDF e o OSB, que passaram a ser armazenados bem próximos do alcance dos funcionários diminuindo o tempo de locomoção. A segunda modificação significativa foi o espaçamento entre os demais setores e a introdução de esteiras com o objetivo de facilitar o transporte das peças principalmente as maiores e mais pesadas. Para isto, foi 
necessário também alterar a posição das mesas para que fosse possível dar-se sequência ao processo.

A disposição das mesas do setor de colagem foi alterada com o intuito de facilitar a passagem das peças pelo setor. E ainda o setor de corte que contava com quatro mesas de três metros tinha dificuldades em lidar com peças muito grandes, passando a contar com uma mesa de nove metros e outra com cinco metros, facilitando assim o plano de corte.

As costureiras por desenvolverem o modelo de sofá sempre em duplas foram dispostas lado a lado, facilitando o processo e a troca de peças. Tais alterações proporcionaram maior organização, agilidade de transporte das peças entre os setores, menos tempo dispendido no transporte interno de peças, melhorando-se a sequência do processo e reduzindo-se o tempo de atravessamento das peças na fábrica. No entanto, antes da implantação do TPC, um grande número de peças (estruturas de madeira com espuma) persistia em permanecer acumuladas entre os setores, principalmente no setor de colagem.

Após a chegada da ordem de programação os dois setores iniciais de corte de tecido e marcenaria começavam a produzir simultaneamente. A madeira, por disponibilidade em estoque, era empregada na produção da estrutura semiacabada que em sequência era encaminhada ao setor de montagem inicial e colagem, anterior a estofaria. Entretanto, contatou-se que estas peças passavam um longo período de espera por falta de alguma matéria prima, principalmente o tecido, na estofaria, para a montagem final do estofado.

Alguns fatores foram levantados pela falha na previsão adequada a demanda de tecidos:

- Alta obsolescência com referência ao mercado e suas tendências (a empresa conta com mais de 570 revestimentos (tecidos) em sua cartela de mostruário);

- Um percentual significativo dos revestimentos não apresentava um consumo médio constante, acarretando picos de vendas dos mais variados itens, em consequência ás tendências de mercado;

- Longo tempo de transporte de fornecedores localizados no exterior, região Sudeste e Sudoeste (de quatro dias) até fábrica e para este processo dependendo-se unicamente de duas transportadoras;

- Longo tempo até a fabricação e liberação do pedido para transporte pelo fornecedor (de 20 a 50 dias);

- Percentual acentuado de tecidos importados com longos prazos para recebimento;

- Muitos revestimentos com valores mínimos de metragem para compra, ou com preços significativamente reduzidos se comprados em grande metragem demandando assim um alto valor de investimento de estoques;

- Rolos com metragens grandes e defeitos nos tecidos ao longo do rolo, principalmente de tonalidade.

Todavia, a empresa tem necessidade de manter um grande "mix" de revestimentos em estoque, devido a valores mínimos de metragem para compra ou pela possibilidade de barganha 
de preços. No período de aplicação deste estudo, em 2014, o estoque de tecidos representava $56,42 \%$ do total dos estoques de matéria-prima.

Na Tabela 2 é possível verificar a participação no custo total do tecido empregado do produto em relação as demais matérias-primas, para análise foram tomados como base três modelos de estofados em tamanho padrão de três lugares.

Tabela 2: Participação em porcentagem da MP (matéria-prima) no custo total do produto.

\begin{tabular}{c|c|c|c}
\hline Grupo MP & $\mathrm{P} 1$ & $\mathrm{P} 2$ & $\mathrm{P} 3$ \\
\hline Madeiras/ compensados & $10,75 \%$ & $10,54 \%$ & $6,45 \%$ \\
\hline Componentes/ Montagem & $5,19 \%$ & $7,55 \%$ & $6,38 \%$ \\
\hline Revestimentos & $35,39 \%$ & $34,76 \%$ & $31,65 \%$ \\
\hline Espuma/fibras & $27,71 \%$ & $35,07 \%$ & $29,16 \%$ \\
\hline Acessórios/opcionais & $12,95 \%$ & $5,75 \%$ & $15,71 \%$ \\
\hline Embalagens & $3,35 \%$ & $2,67 \%$ & $2,99 \%$ \\
\hline Complementos & $4,66 \%$ & $3,66 \%$ & $7,66 \%$ \\
\hline Custo total MP & $100,00 \%$ & $100,00 \%$ & $100,00 \%$ \\
\hline
\end{tabular}

Fonte: Elaboração própria

Ainda em relação aos revestimentos, pela organização não possuir demanda do estoque obsoleto destes e por não possuir parcerias com concorrentes para troca de tecidos entre as empresas do segmento, a empresa realiza a venda dos produtos no estilo de patchwork "trabalho com retalhos", o qual é uma técnica que une tecidos com uma infinidade de formatos e cores variados, bem aceitos pelo mercado no momento de realização desta pesquisa, representando em torno de $10 \%$ de utilização dos tecidos obsoletos em estoque.

\subsection{Aplicação do TPC}

Aplicou-se na empresa a lógica TPC (Tambor-Pulmão-Corda). A aplicação foi realizada em abril de 2013, com o intuito de reduzir-se o número de peças (estruturas de madeira com espuma) que permaneciam acumuladas entre os setores, principalmente após o setor específico de colagem, aguardando na estofaria a disponibilidade de tecido para a montagem final, demonstrando-se o dessincronizarão dos fluxos produtivos entre os centros de trabalho. Para a implantação foi necessária a liberação de todos os funcionários, com exceção do setor de corte por três dias consecutivos, justamente com o intuito de organizar a produção e fazer com que o setor de corte conseguisse analisar e cortar as programações antes dos demais setores. Assim, quando os demais setores voltassem, seria possível sincronizar a produção fazendo com que o corte fosse o tambor e somente após fosse liberada a produção para os demais setores.

Uma consultoria externa realinhou todos os processos. A consultoria foi fundamental para a divulgação do novo processo de programação da produção entre os funcionários, além do acompanhamento, o qual teve duração de aproximadamente um ano, contando com 16 horas semanais. No tocante à aplicação da metodologia efetivamente, o setor estabelecido como tambor foi o de corte de tecido, portanto, assim que a programação passasse pelo setor, ou seja, fosse cortado o tecido na metragem suficiente e em boas condições disponível, a mesma era repassada ao setor de marcenaria dando início aos processos em sequência, liberando a restrição (operação de corte de tecido) a iniciar a produção da estrutura do estofado. 
A corda responsável por sincronizar a chegada de itens para montagens foi definida como a operação de liberação da capa para à estofaria. Sincronizando as operações gargalo (o corte e costura do tecido) e as operações não gargalo (produção da estrutura de madeira com espuma).

O pulmão representa o estoque de capas cortadas disponíveis para o setor de costura, mantendo-se assim um estoque protetivo de capas cortadas ditando e mantendo o ritmo de produção constante dos demais setores, conforme a Figura 3.

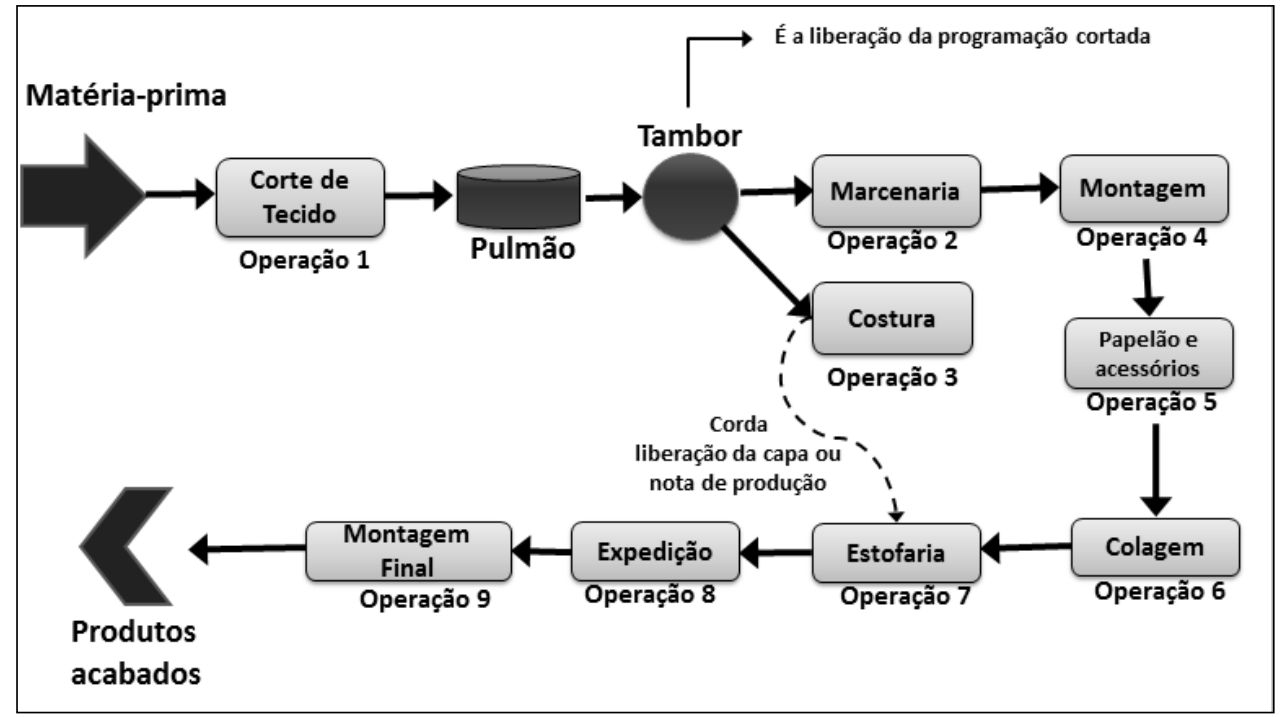

Figura 3: A implantação do TPC. Fonte: Elaboração própria

A programação da produção ocorre em lotes de processamento de estofados de 48 peças até a operação de colagem, posteriormente seguindo-se com fluxo unitário de peças por cliente no setor de costura, estofaria e expedição.

Alguns impactos positivos relacionados a esta alteração foram:

- Redução de investimentos em peças em processo de produção paradas aguardando a chegada de matéria prima no setor de estofaria em 27\%);

- Redução do número de peças paradas nos primeiros seis meses em 62,5\%;

- Os pedidos somente são liberados para a fabricação de sua estrutura principal quando for detectado que há matéria prima suficiente e em boa qualidade para a fabricação de todo o produto completo;

- Redução de $20 \%$ de desperdício no tempo de mão de obra empregada em atividades que no momento não agregavam valor.

Entre as vantagens observadas pela aplicação do TPC foi a diminuição de peças acumuladas entre os setores, constatando-se uma redução de $90 \%$ de peças que anteriormente permaneciam aguardando entre processos. Por exemplo, para uma programação diária de 45 peças (em média), cerca de 10 a 15 peças ficavam entre os setores aguardando alguma peça complementar, sendo que após seis meses de implantação do sistema, menos de três peças permaneciam aguardando entre os setores. 
Como mencionado previamente, o TPC foi implantado em abril, verificando-se na Tabela 3, a redução do lead time de produção e de peças aguardando entre setores, bem como o retrabalho foram reduzidos, consequentemente alcançando-se redução do tempo de resposta de atendimento aos clientes, produzindo-se em média diariamente 39 estofados no mês de janeiro de 2013 e passando-se para um pico de 47 em outubro de 2013 e fevereiro de 2014.

Tabela 3: Melhorias observadas antes e após a implantação do TPC

\begin{tabular}{c|c|c|c}
\hline Período & $\begin{array}{c}\text { Peças programadas } \\
\text { por dia (média) }\end{array}$ & Peças aguardando MP & Retrabalhos \\
\hline jan/13 & 39 & $26 \%$ & $10 \%$ \\
\hline fev/13 & 38 & $24 \%$ & $8 \%$ \\
\hline mar/13 & 35 & $20 \%$ & $6 \%$ \\
\hline abr/13 & 33 & $24 \%$ & $9 \%$ \\
\hline mai/13 & 38 & $13 \%$ & $3 \%$ \\
\hline jun/13 & 40 & $8 \%$ & $0 \%$ \\
\hline jul/13 & 42 & $2 \%$ & $0 \%$ \\
\hline ago/13 & 40 & $3 \%$ & $0 \%$ \\
\hline set/13 & 45 & $4 \%$ & $0 \%$ \\
\hline out/13 & 47 & $0 \%$ & $2 \%$ \\
\hline nov/13 & 45 & $0 \%$ & $0 \%$ \\
\hline dez/13 & 45 & $0 \%$ & $2 \%$ \\
\hline jan/14 & 46 & $0 \%$ & $0 \%$ \\
\hline fev/14 & 47 & $0 \%$ & $2 \%$ \\
\hline mar/14 & 46 & $0 \%$ & $0 \%$ \\
\hline
\end{tabular}

Fonte: Elaboração própria

A quantidade de estofados produzidos diariamente aumentou em $118 \%$, passando a programação inicial de aproximadamente 39 peças/dia para 46 peças/dia, não sendo necessária a aquisição de novas máquinas ou contratação de mais funcionários.

Antes da aplicação do TPC eram produzidos em média 4,87 sofás/hora no gargalo, passando para 5,75 sofás/hora após a mudança interna, representando um aumento de $18 \%$ de produtividade diariamente, de 39 peças acabadas/dia para de 46 peças acabadas/dia, aumentando a receita direta da empresa em aproximadamente $19 \%$.

Como impacto negativo, observou-se a perda do faturamento por três dias e a liberação dos funcionários que aconteceu por conta da empresa.

Ainda, entre as dificuldades enfrentadas pela empresa durante o processo de implantação, foi observada a resistência à mudança de alguns funcionários, principalmente os com maior tempo de carreira na empresa (acima de cinco anos), sendo que estes representam $48 \%$ do total. Os funcionários em geral estavam acostumados a seguir a sua própria sequência, e a fazerem o seu próprio ritmo de produção, porém, com o sequenciamento implantado, todos os setores ficaram subordinados ao setor de corte de tecido. De qualquer forma, este fato foi superado com o acompanhamento de todo o grupo e da divulgação dos objetivos da implantação e da importância para a empresa como um todo e conscientização de toda a equipe.

Quanto ao controle de qualidade, este passou a ser mais rigoroso, de modo que produtos defeituosos não viessem a desperdiçar a capacidade do recurso gargalo e prejudicar o ganho direto 
da empresa, realizando-se inspeções totais na chegada da mercadoria nos estoques e na saída dos produtos em processamento de cada setor e por fim, antes da embalagem do estofado.

\section{DISCUSSÃO}

Entre os pontos negativos observados antes da implantação no TPC estava o acúmulo de peças paradas entre os processos (estruturas de madeira com espuma), principalmente após o setor colagem, incorrendo a empresa em um grande montante de matéria prima investida nestas peças. Por falta de sincronização entre as linhas de produção da capa das almofadas e da estrutura de madeira, normalmente as estruturas permaneciam um longo período esperando por pelo tecido, atrasando a montagem final do estofado e a entrega ao consumidor.

Para tanto, empregou-se como solução a metodologia TPC, que contribui para melhoria tanto no aumento da produção, mas principalmente no sequenciamento da mesma, de tal modo que se reduziu o tempo dispendido em movimentação interna de funcionários na procura por peças, bem como houve redução de estoques de peças em processos e o número de peças refugadas, que em sua pluralidade foram alcançados no quarto mês de utilização da programação da produção através do TPC. Outro fator relevante percebido foi a diminuição de stress ou correria na hora de atender aqueles pedidos parados entre os processos ocasionando o atraso na entrega aos clientes.

Como desafios para a aplicação, observou-se a resistência à mudança, principalmente de funcionários que estavam acostumados a seguir a sua própria sequência, sendo importante o acompanhamento, divulgação e a conscientização de todos, de modo a quebrar modelos mentais e tornar clara a importância de tais mudanças.

Entre as implicações gerenciais, ressaltam-se benefícios na organização da produção, pois a metodologia permite que os gestores saibam o que é realmente necessário produzir em determinados momentos, ter uma sequência, e consequentemente menos urgências por falhas de previsão. É relevante para que os empresários e administradores em geral de empresas de produção compreendam que a ferramenta possibilita a redução de tempo despendido no processo como um todo, redução de lead time, redução de peças paradas entre os setores, sequenciamento da produção, organização e previsibilidade quanto ao prazo de entrega dos pedidos.

Além disso, o TPC possibilita a melhoria da tomada de decisão e planejamento das ações em caso de atraso na produção por quebra de máquina ou defeitos, e o gargalo não perde tempo de produção por qualquer parada imprevista que ocorra devido ao pulmão. Ainda há informação do surgimento de oportunidades de aceitar mais pedidos ou pedidos com urgência, verificando-se com antecedência se há ou não capacidade, conforme o gargalo.

No entanto, para que a programação TPC forneça resultados, é imprescindível que o processo seja diariamente acompanhado e reavaliado, que sejam analisadas as restrições do sistema e o tamanho dos pulmões para que o processo não se perca com o tempo e tenha uma continuidade. 


\section{CONSIDERAÇÕES FINAIS}

Esta pesquisa teve por objetivo descrever uma implantação da lógica TPC em uma empresa da indústria moveleira. Os objetivos específicos foram: descrever os setores e o processo produtivo da empresa; descrever os preparativos e procedimentos para implantação do TPC; e analisar os impactos positivos e negativos da implantação.

Para tanto foi realizado um estudo de caso simples, descritivo, em uma empresa que produz estofados make-to-order, pertencente ao polo moveleiro de Bento Gonçalves. Foram analisados dados fornecidos pela empresa bem como foram entrevistados os principais colaboradores envolvidos na aplicação do TPC, como o gerente de produção, diretor da empresa e os supervisores de produção.

Verificou-se e evidenciou-se o sucesso da aplicação da metodologia de programação da produção Tambor-Pulmão-Corda, não somente na redução de custos gerais da empresa como também na organização, sequenciamento do fluxo e identificação de restrições do sistema.

As ideias da TOC e a metodologia TPC permitiram a identificação e exploração do gargalo, melhorando-se a função processo, ou seja, o fluxo dos objetos de trabalho pelo sistema, permitindo que a empresa obtivesse melhoria no tempo de resposta aos clientes, mais qualidade e consequentemente aumento de ganho.

Todavia, observou-se alguns desafios como a compreensão e divulgação das mudanças para a equipe de modo a tornar os colaboradores mais resilientes e perceberem os benefícios e colaborarem com a aplicação da metodologia.

A contribuição desta pesquisa revela-se para gestores de produção em geral que queiram aumentar o ganho de suas fábricas, pois através dos resultados aqui encontrados, constatou-se que a metodologia pode proporcionar benefícios como redução do lead time, dos retrabalhos, redução de estoques entre processos e aumento da produção diária.

Ainda considerou-se que a respectiva pesquisa é importante no âmbito acadêmico, pois foram encontrados poucos estudos de aplicação prática da metodologia, dos quais a maioria eram estudos teóricos, de simulação ou de comparação do TPC com outras metodologias como o MRP.

Quanto ao fato da organização não realizar previsões de demanda e atender por pedido, esta baseia a compra de matéria-prima pelo consumo médio de três meses anteriores e, portanto, mantém altos níveis de estoque, sugerindo-se como futura pesquisa um estudo acerca da possibilidade de integração do já existente TPC com a aplicação do sistema de programação da produção MRP II (Manufacturing Resources Planning), o qual é um software utilizado na gestão de produção, com foco central na resolução das dificuldades encontradas no chão de fábrica.

A intenção é buscar um sistema híbrido, com sincronia entre compras e produção que atenda a real necessidade e ao mesmo tempo reduza inventário, obtendo-se mais informações das necessidades de compra considerando os estoques já existentes bem como outros processos necessários.

Como limitações da pesquisa pode-se mencionar que os resultados verificados são respectivos ao contexto em análise. Tal fato requer outros estudos para comprovação dos benefícios da implantação do TPC, não sendo possível a generalização dos resultados aqui constatados. Portanto, como oportunidade de pesquisas propõe-se estudos aprofundando-se nas 
técnicas da Teoria das Restrições (TOC), como aplicação de indicadores de desempenho tais como Inventário-Dinheiro-Dia (IDD) e Ganho-Dinheiro-Dia (GDD) que visa, contribuir no controle dos estoques e aumento de ganho na restrição.

\section{REFERÊNCIAS}

1. ACEVEDO, C.R.; NOHARA, J. J. Como fazer monografias: TCC, dissertações e teses. 4. ed. São Paulo: Atlas, 2013.

2. ANTUNES, J. A. V. Em Direção a uma Teoria Geral do Processo na Administração da Produção: uma Discussão Sobre a Possibilidade de Unificação da Teoria das Restrições e da Teoria que Sustenta a Construção dos Sistemas de Produção com Estoque Zero. 1998. 407f. Tese (Doutorado em Administração), Programa de Pós-Graduação em Administração, UFRGS, Universidade Federal do Rio Grande do Sul, RS, 1998.

3. ATWATER J.B.; CHAKRAVORTY, S.S. A study of the utilization of capacity constrained resources in drum-buffer-rope systems, Production and Operations Management, v.11, n.2, p.259-273, 2002.

4. BOYD, L.H.; GUPTA, M.C. Constraints management: what is the theory?, International Journal of Operations \& Production Management, v. 24, n. 4, p. 350-71, 2004.

5. CHAKRAVORTY, S. S.; ATWATER, J. B. The impact of free goods on the performance of drumbuffer-rope scheduling systems, International Journal of Production Economics, v. 95, n. 3, p. 347-357, 2005.

6. GIL, A.C. Como elaborar projetos de pesquisa. 5ed. São Paulo: Atlas, 2010.

7. GEORGIADIS, P.; POLITOU, A. Dynamic Drum-Buffer-Rope approach for production planning and control in capacitated flow-shop manufacturing systems, Computers \& Industrial Engineering, v. 65, p. 689-703, 2013.

8. GOLDRATT, E.M.; COX, J. A Meta: um processo de melhoria contínua, Nobel, São Paulo, SP, 2002.

9. IEMI - Instituto de Estudos e Marketing Industrial. Relatório Setorial da Indústria de Móveis no Brasil, Free Press Editorial, v.9, n.9, p.1-146, 2014.

10. MABIN, V.J.; BALDERSTONE, S.J. The performance of the theory of constraints methodology: analysis and discussion of successful TOC applications, International Journal of Operations \& Production Management, v. 23, n.6, p. 568-595, 2003.

11. MEDEIROS. J.B. Redação Cientifica: a prática de fichamentos, resumos, resenhas. 11. Ed. São Paulo: Atlas, 2011.

12. MOVERGS - Associação das Indústrias de Móveis do Estado do Rio Grande do Sul. Relatório Setorial 2013 - Móveis do RS. 2013. Disponível em:< http://www.movergs.com.br/views/ imagem_pdf.php?pasta=relatorio_setorial2013>. Acesso em: 09 jul. 2014

13. OLIVEIRA. M. M. Como fazer uma pesquisa qualitativa. 3a ed. Petrópolis, RJ: Vozes, 2010.

14. PANIZZOLO, R.; GARENGO, P. Using Theory of Constraints to Control Manufacturing Systems: A Conceptual Model, Journal of Industrial Engineering and Management, v.2, n.3, p.1-9, 2013. 
15. PeReIRA, G.; SELLITTO, M.; BORCHARDT, M.; GEIGER, A. Procurement cost reduction for customized non-critical items in an automotive supply chain: An action research project. Industrial Marketing Management, v. 40, n. 1, p. 28-35, 2011.

16. REID, R.A. Applying the TOC five-step focusing process in the service sector: a banking subsystem, Managing Service Quality, v.17, n.2, p. 209-34, 2008.

17. SCHRAGENHEIM, E; RONEN, B. Drum-Buffer-Rope Shopfloor Control, Production and Inventory Management Journal, v.31, n.3, p. 18-22, 1990.

18. SILVA, E.L.; MENEZES, E.M. Metodologia da Pesquisa e elaboração da dissertação. 4. ed. Florianópolis: UFSC, 2005.

19. SOUZA, A.A.C. Aplicação da metodologia Tambor - Pulmão - Corda (TPC) com supermercado na gestão de manufatura de eletrodos de grafite das unidades de Candeias e Monterrey da Graftech International Ltd.112 f.2006. Dissertação (Mestrado em Administração), Escola de Administração, Universidade Federal da Bahia, UFBA, Bahia, BA, 2006.

20. SOUZA, M.B. Clusters como estratégia de desenvolvimento de pequenas e médias empresas: um estudo exploratório do caso moveleiro do município de Colatina-ES. 2003.102f. Dissertação(Mestrado Executivo), Escola Brasileira de Administração pública e de empresas, Fundação Getúlio Vargas, FGV, Rio de Janeiro, RJ, 2003.

21. SRINIVASAN, M. M.; JONES, D.; MILLER, A. Applying the theory of constraints principles and lean thinking at the marine corps maintenance center, Defense Acquisition Review Journal, 2004.

22. STEELE, D. C.; PHILLIPOOM, P. R.; MALHOTRA, M. K.; FRY, T. D. Comparisons between drumbuffer-rope and material requirements planning: A case study, International Journal of Production Research, v.43, n.15, p.3181-3208, 2007.

23. TULASI, L. C; RAO, R.A. Review on Theory of Constraints, International Journal of Advances in Engineering \& Technology, v.3, n.1, p. 334-344, 2012.

24. WATSON, K. J.; BLACKSTONE, J. H.; GARDINER, S. C. The evolution of a management philosophy: the theory of constraints, Journal of Operations Management, n.25, p.387-402, 2007.

25. WU, S.; MORRIS, J.S.; GORDON, T.M. A Simulation Analysis of the Effectiveness of DrumBuffer-Rope Scheduling in Furniture Manufacturing, Computers \& Industrial Engineering, v.26, n.4, p.p. 757-764, 1994. 